\title{
Supporting the implementation of guidelines to prevent mother-to-child-transmission of HIV in Malawi: a multi-case study
}

\author{
Chifundo Zimba1, Gwen Sherwood ${ }^{2}$, Barbara Mark², Jeenifer Leeman ${ }^{2}$
}

1. University of North Carolina Project, Lilongwe, Malawi and University of North Carolina at Chapel Hill, School of Nursing, Chapel Hill, NC, USA

2. University of North Carolina at Chapel Hill, Nursing

Correspondence: Chifundo Zimba (czimba@unclilongwe.org)

\begin{abstract}
Background
Abstract

High HIV infection and fertility rates contributed to over 12,000 children acquiring HIV from their mothers in 2011 in Malawi. To prevent mother-to-child transmission of HIV, Malawi adopted the Option B+ guidelines, and for three years, the University of North Carolina (UNC) Project provided support to strengthen guideline implementation in 134 health centres. Little is known about how implementation support strategies are delivered in low resource countries or contextual factors that may influence their delivery. The limited descriptions of support strategies and salient contextual factors limits efforts to replicate, target, and further refine strategies. Guided by the Interactive Systems Framework for Dissemination and Implementation, this study describes factors influencing implementation of support strategies and how they impacted health center staff capacity to implement Option B+ in Malawi.

Methods

A qualitative multi-case study design was applied. Data were collected through site visits to 4 heath centres (2 low- and 2-high performing centres). We interviewed 18 support providers and recipients between October 2014 and October 2015. Data were analysed using content, thematic, and cross-case analysis.

Results

Four categories of strategies were used to support Option B+ guidelines implementation: training, technical assistance (TA), tools, and resources. All heath-centres implemented Option B+ guidelines for care provided between the antenatal and labor and delivery periods. Gaps in Option B+ implementation occurred during community activities and during post-delivery care, including gaps in testing of children to ascertain their HIV status at 6 weeks, 12 months, and 24 months. Salient contextual factors included staffing shortages, transportation challenges, limited space and infrastructure, limited stocks of HIV testing kits, and large patient populations. Conclusions

Understanding factors that influence implementation support strategies and delivery of the Option B+ guidelines, such as availability of staff and other materials/drug resources, is critical to designing effective implementation support for low resource settings.
\end{abstract}

Keywords: Qualitative; Option B+; Guidelines; HIV, Prevention-of-mother-to child- transmission.

\section{Introduction}

In 2016, over half of all new HIV infections in Sub-Saharan Africa occurred in women ${ }^{1}$. In Malawi, $10.8 \%$ of women aged 15-49 years were infected with $\mathrm{HIV}^{2}$ with over 12,000 Malawian children acquiring HIV from their mothers in $2011^{3}$. To reduce the transmission of HIV to children, the Malawi Ministry of Health $(\mathrm{MoH})$ adopted the "Option $\mathrm{B}+$ " guidelines. The guidelines recommend testing all pregnant women for HIV, and if infected, providing them with lifelong antiretroviral therapy (ART) and their infants with nevirapine ${ }^{4}$. Option $\mathrm{B}+$ guidelines have the potential to prevent $95 \%$ of mother-to-child transmission of HIV infections ${ }^{5,6}$.

Since 1989, the Malawi MoH has partnered with the University of North Carolina (UNC) Project to improve the health of Malawians. In 2001, the UNC Project established Malawi's first Prevention of Mother-to-Child-Transmission (PMTCT) of HIV program in Lilongwe, Malawi's capital city $^{7}$. To support Option B+ implementation, the UNC Project and $\mathrm{MoH}$ adapted strategies that were used to scale up PMTCT services in South Africa. These support strategies included training for frontline personnel and periodic technical assistance and performance evaluation visits for health centres. During these visits, those providing technical assistance used a checklist to ensure the completion of a standardized set of activities at each visit ${ }^{8}$. By 2013, the UNC Project's PMTCT program was providing training, technical assistance and other implementation support to 134 health facilities ${ }^{8}$.

With support from the UNC Project, Malawian health centres have successfully implemented elements of the Option B+ guidelines. A 2015 study found that $87 \%$ of pregnant women received HIV testing and counseling (HTC), 96\% of $\mathrm{HIV}$-infected women received antiretroviral therapy (ART), and $100 \%$ of their infants received nevirapine ${ }^{8}$. Still, gaps in Option $\mathrm{B}+$ implementation persist, particularly during the postnatal period. In 2014 , only $18-20 \%$ of children born to HIV + mothers were tested for HIV by the age of two months ${ }^{1,9}$, and by age $12-18$ months, $17 \%$ of children born to HIV+ mothers had become infected ${ }^{1}$.

To better understand factors influencing implementation, 
this paper reports the findings of a multi-case study to gain an in-depth understanding of health centres' experience with support strategies and their impact on Option B+ implementation. Results can inform future implementation strategies to realize the full potential of Option $\mathrm{B}+$ guidelines and thereby reduce the number of HIV infected children globally.

\section{Conceptual Framework}

Figure 1 provides an overview of this study's conceptual framework, which builds on Wandersman et al.'s Interactive Systems Framework (ISF) for Dissemination and Implementation. ${ }^{10,11}$ The ISF describes how three systems interact to translate evidence-based guidelines into widespread practice. The Synthesis and Translation System (i.e., Malawi's MoH), synthesizes research evidence and translates it into guidelines that delivery systems (i.e., health centres) are intended to implement in practice. Support systems (i.e., UNC Project) provide training, Technical Assistance (TA), tools, and other strategies to support the delivery system's implementation of guidelines and improve health outcomes. This study examined how the support and delivery systems interacted to implement Option B + guidelines in Malawi and the contextual factors that influenced both implementation and support.

Study aims were to (1) describe $\mathrm{MoH}$ and UNC Project staffs' experience with implementation of support strategies and their impact on health centres' capacity to implement Option B+, (2) identify gaps in Option B + implementation, and (3) explore contextual factors that influenced both support strategies and Option B+ implementation.

\section{Methods \\ Design}

This study applied a qualitative descriptive exploratory, multiple-case study design ${ }^{12}$ and was approved by two Institutional Review Boards: The University of North

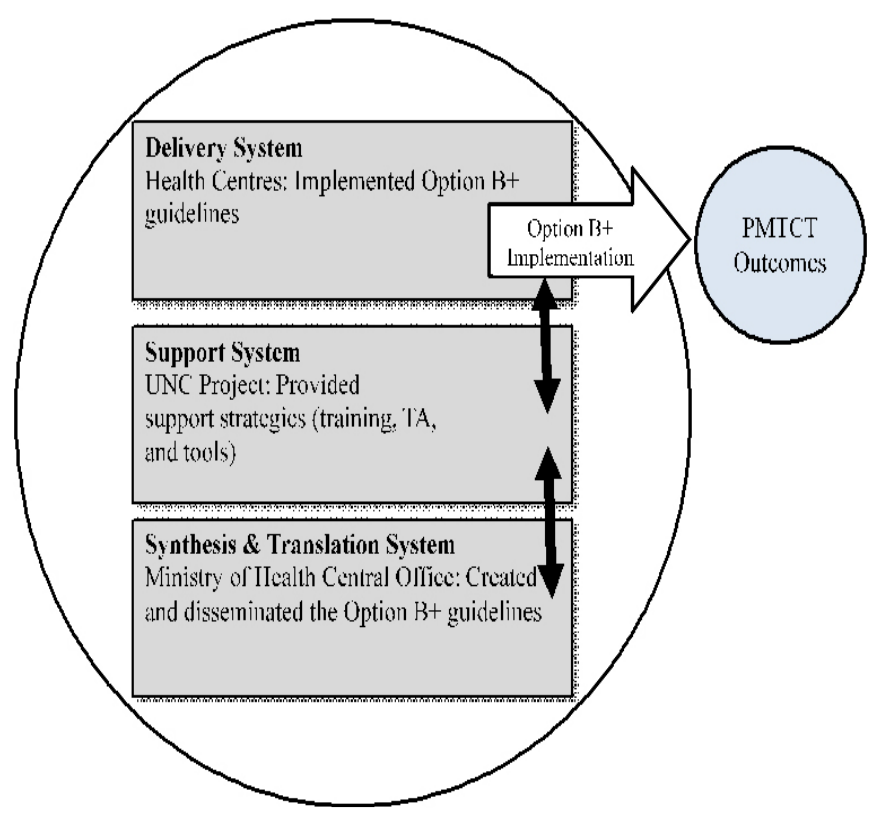

Figure 1: The ISF applied to implementation of the Option B+ Guidelines in Malawi ${ }^{10,11}$
Carolina at Chapel Hill Research and Ethics Committee (approval \#14-1441) and the Malawi National Health Sciences Research and Ethics Committee (approval \# 1302). Permission was granted by the Malawi MoH HIV/ AIDS office, district health offices, and the four study health centres through their directors and managers. Study informants completed written informed consent.

\section{Sampling process and study setting}

We purposively sampled four of $134 \mathrm{MoH}$ centres in 3 districts within the central region of Malawi and treated each as a case. To be included, centres had (1) received implementation support strategies from UNC Project; (2) adopted and implemented the Option $\mathrm{B}+$ guidelines for at least one year; (3) provided antenatal, labor and delivery, postnatal, and under-five services; and (4) met minimum staffing norms of two nurses/midwives, two clinicians, one assistant environmental health officer, and one health surveillance assistant per 1000 households.

Of the eleven health centres meeting primary inclusion criteria, two high-performing (HP) and two low-performing (LP) centres were purposively sampled, determined by the percentage of pregnant women they tested for HIV according to annual $\mathrm{MoH}$ data, with $\geq 80 \%$ rated as high performing and $\leq 60 \%$ as low performing.

Key Informants. Within each health centre, key informants were selected using a snowball sampling technique ${ }^{13}$ based on who had the most experience supporting and/ or implementing the Option $\mathrm{B}+$ guidelines. Eighteen informants were interviewed: 10 support providers and eight health centre staff ( 2 per centre).

\section{Data collection}

Twenty-one in-depth interviews were done with $18 \mathrm{key}$ informants (3 support providers worked with two centres and therefore were interviewed twice) using open-ended questions. A semi-structured interview guide was developed to capture descriptive information about informants' experience with implementation support strategies, health centres implementation of Option $\mathrm{B}+$ guidelines, and contextual factors influencing delivery of support strategies or implementation of guidelines. The interview guide was piloted with staff in two health centres not participating in the study. To ensure privacy and confidentiality, all informants were identified by numbers and interviews were done in private rooms chosen by the informant. All interviews were conducted in English (Malawian official language), with some interviews also including some Chichewa (Malawian national language). All interviews were audio-recorded and supplemented with field notes. Audio recordings were then transferred into an encrypted computer with passwords known by the researchers.

\section{Data analysis}

Data were transcribed verbatim and transcripts verified for completeness and clarity. The first author and a research assistant independently translated interview content captured in Chichewa into English, compared translations, and reconciled discrepancies. Data from each health centre were embedded into a case-description data set. ${ }^{12,14,15}$ The first author coded data in Atlas.ti 7.5.7 using a content thematic analysis ${ }^{16}$ guided by the study's conceptual framework (see Figure 1). Support strategies were coded according to type (e.g., training, tools) and contextual factors were coded inductively, as they emerged. Each component of the Option $\mathrm{B}+$ guidelines was coded and then scored on a https://dx.doi.org/10.4314/mmj.v33i3.5 
scale of 0 to 3 , ranging from not implemented to implemented all the time. For each case, the implementation score for each component was calculated as the mean of respondent scores and the implementation score overall was calculated as the mean across components. The second author independently coded three transcripts, and with the first author, identified emerging themes to ensure consistent coding. A summary description of each health centre (case) was then developed and used for a cross-case synthesis that explored similarities or differences within, between, and among the cases. ${ }^{12}$

\section{Results}

Table 1 provides an overview of the four participating health centres and key informants. Informants included 17 nurse midwives and 1 medical assistant $(\mathrm{N}=18)$. Nine self-identified as males and 9 as females. Professional work experience ranged from 4 to 45 years, most working fewer than 20 years.

\section{Support strategies}

Informants described four types of support strategies: Tools, Training, TA, and Resources.

Tools. The Malawi MoH created manuals and guidelines with detailed recommendations for integrating the Option $\mathrm{B}+$ guidelines into existing maternal and childcare services. The UNC Project developed standard operating procedures (SOPs), flow charts, and posters. The UNC project used the manuals and guidelines to educate health centre staff on PMCTC. They gave the health centres SOPs, flow charts, and posters to aid them in integrating PMTCT into routine practice. Health centre staff reported that these tools reminded them of essential tasks:

UNC Project provided us with guidelines... on issues of EID [early infant diagnosis], they provided us with posters which have been pasted all over to say, how do you collect a DBS [dried blood spot] sample, how do you go about with an HIV positive pregnant mother... so it's like we have the resources, which can make us capable to implement the Option B+ (registered nurse midwife, lowperforming centre)

Training. Four types of trainings were offered to health centre staff: (1) a two-week course on implementing Option $\mathrm{B}+$ guidelines for nurses/clinicians new to PMTCT; (2) a one-week refresher course for those previously trained; (3) a one-week early infant diagnosis course for Health Surveillance Assistants (HSAs) to identify, collect, and process HIV samples from HIV-exposed children; and (4) a one-day orientation course for data clerks for monitoring and evaluating guideline implementation. All required travel except the one-day orientation course. Informants reported that training improved implementation of Option $\mathrm{B}+$ guidelines:

I feel it is the training of the option $B+$ helped a lot on the implementation of Option B+ guidelines.... this is because they now know how to give the Option B+ services to the mother. They are now able on their own to conduct Option B+ activities (registered nurse, high-performing centre).

Hospital administrators, environmental health officers,

Table 1. Characteristics of the study health centres. All adopted Option B+ guidelines in 2011

\begin{tabular}{|c|c|c|c|c|}
\hline Characteristics & High Performing 1 & High Performing 2 & Low Performing 1 & Low Performing 2 \\
\hline $\begin{array}{l}\text { Clinic Age: } \\
\text { - Year Opened } \\
\text { - Years receiving } \\
\text { TA }\end{array}$ & $\begin{array}{l}1979 \\
5 \text { years }\end{array}$ & $\begin{array}{l}1984 \\
3 \text { years }\end{array}$ & $\begin{array}{l}1983 \\
3 \text { years }\end{array}$ & $\begin{array}{l}1984 \\
3 \text { years }\end{array}$ \\
\hline $\begin{array}{l}\text { Clinic Location } \\
\text { - Distance from } \\
\text { well-paved road }\end{array}$ & Just off. & Just off & $12 \mathrm{~km}$ & $10 \mathrm{~km}$ \\
\hline $\begin{array}{l}\text { Clinic Size } \\
\text { - Staff trained in } \\
\text { Option B+ }\end{array}$ & $\begin{array}{l}7 \text { Nurses (1=RN; } 6 \text { NMTs) } \\
1 \text { Medical Assistant } \\
7 \text { HSAs } \\
2 \text { counselors }\end{array}$ & $\begin{array}{l}3 \text { Nurses (NMTs) } \\
2 \text { Medical Assistants } \\
8 \text { counselors } \\
1=\text { Volunteers }\end{array}$ & $\begin{array}{l}2 \text { Nurses (NMTs) } \\
11 \text { HSAs } \\
3 \text { counselors } \\
1 \text { Statistical Clerk }\end{array}$ & $\begin{array}{l}2 \text { Nurses (NMTs) } \\
1 \text { Medical Assistant } \\
2 \text { HSAs } \\
4 \text { counselors }\end{array}$ \\
\hline
\end{tabular}

NMTs= Nurse/Midwife Technicians, RN= Registered Nurse, HSAs= Health Surveillance Assistants, $\mathrm{TA}=$ Technical Assistance 


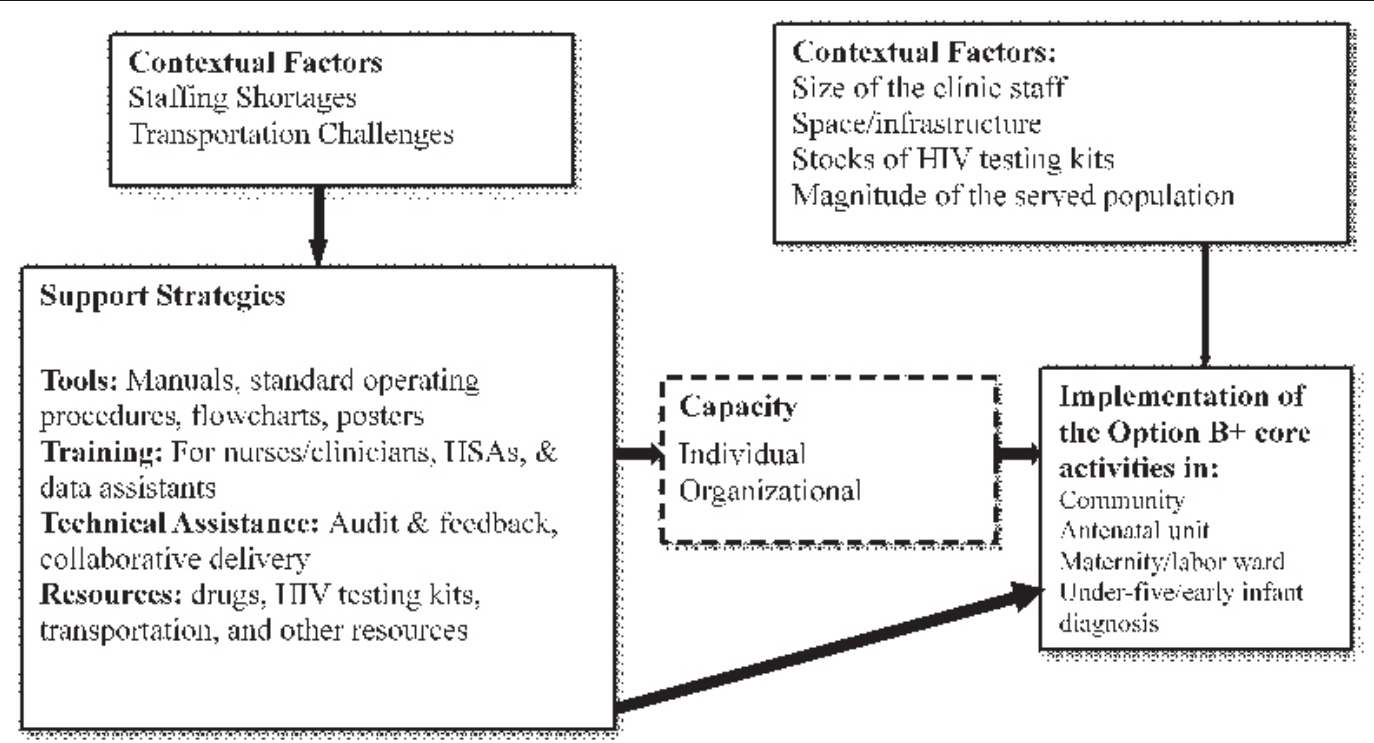

Figure 2: The UNC Project's implementation strategies and factors that influenced their delivery and Impact

Table 2. Centres' implementation of Option B+ Guideline Core Component

\begin{tabular}{|c|c|c|c|c|}
\hline \multirow[t]{2}{*}{ Option B+ Guideline Core Component } & \multicolumn{4}{|c|}{$\begin{array}{c}{ }^{*} \text { Centre Average Rating } \\
(0=\text { not implemented to } 3=\text { implemented all the } \\
\text { time })\end{array}$} \\
\hline & $\begin{array}{l}{ }^{* *} \mathrm{HP}-1 \\
(\mathrm{n}=6)\end{array}$ & $\begin{array}{l}\mathrm{HP}-2 \\
(\mathrm{n}=5)\end{array}$ & $\begin{array}{l}\mathrm{LP}-1 \\
(\mathrm{n}=5)\end{array}$ & $\begin{array}{l}\text { LP-2 } \\
(n=5)\end{array}$ \\
\hline \multicolumn{5}{|l|}{ Community } \\
\hline - Community sensitization and mobilization & 1 & 3 & 0.2 & 1 \\
\hline \multicolumn{5}{|l|}{ Antenatal, labor and delivery and post delivery periods } \\
\hline - HIV testing of all pregnant and breast-feeding women. & 2.6 & 3 & 2.4 & 3 \\
\hline - Checking health passport to determine HIV status. & 2.6 & 3 & 3 & 3 \\
\hline $\begin{array}{l}\text { - Routinely offering an HIV test through provider-initiated } \\
\text { HIV testing and counseling to all pregnant and breast- } \\
\text { feeding women. }\end{array}$ & 2.8 & 3 & 2.4 & 2.6 \\
\hline $\begin{array}{l}\text { - Conducting health education to inform HIV-infected } \\
\text { women and their family members that ARVs must be } \\
\text { taken every day for life. }\end{array}$ & 3 & 3 & 3 & 3 \\
\hline $\begin{array}{l}\text { - Initiating lifelong ARTto all identified HIV-infected preg- } \\
\text { nant and breastfeeding women within seven days of HIV } \\
\text { diagnosis. }\end{array}$ & 3 & 3 & 3 & 3 \\
\hline $\begin{array}{l}\text { Supplying three } 25 \mathrm{mls} \text { bottles of nevirapine (NVP) } \\
\text { syrup to all HIV-infected women for their HIV-exposed } \\
\text { babies once diagnosed. }\end{array}$ & 3 & 3 & 3 & 3 \\
\hline Initiating integrated mother/infant follow-up scheduling. & 2 & 2.6 & 3 & 2.6 \\
\hline $\begin{array}{l}\text { Post delivery } \\
\text { Ascertaining HIV status for HIV-exposed children by } \\
\text { collecting at least one DNA-PCR sample from each } \\
\text { HIV-exposed child from age of six weeks. }\end{array}$ & 3 & 2.6 & 1.8 & 1.4 \\
\hline $\begin{array}{l}\text { Ascertaining HIV status for all HIV-exposed children at } \\
12 \text { and } 24 \text { months. } \\
\text { Across the continuum }\end{array}$ & 2.6 & 3 & 2.2 & 1.6 \\
\hline $\begin{array}{l}\text { Documenting all rendered } \text { PMTCT }^{* *} \text { activities in correct } \\
\text { registers or cards. }\end{array}$ & 1.5 & 2 & 3 & 1 \\
\hline Overall rating & 2.5 & 2.8 & 2.3 & 2.3 \\
\hline
\end{tabular}


drivers, and hospital attendants were not part of the training, which contributed to implementation issues. For example, drivers had no knowledge about how to manage HIV specimens during transportation to laboratories. Furthermore, off site training pulled staff away leaving health centres short staffed and less able to fully implement Option B+ guidelines.

Support providers also collaborated with health centre staff to deliver services related to the Option $\mathrm{B}+$ guidelines either at a health centre or in the community. A support provider stated:

We had to help with some activities like antenatal
clinics, HIV counseling and testing... follow
up of clients, hands-on on the initiation of
Option B+ as well as the documentation in
the registers... We were working hand-in-hand
with the HS As in checking HIV status for the
mothers in their health passport book....We were
assisting the nurses and the counselors with the
outreach activities....We did all these activities
in the presence of health care workers in case
they bad forgotten the procedure, they could learn
from us (nurse midwife technician, high-
performing centre).

The amount of time TA providers spent at each health centre ranged from an average of 1 to 6 hours per month. The focus of the TA visits also varied with TA providers focusing the most time on documentation (i.e., checking registers, cards, and report writing). The second area where TA providers focused their time was early infant diagnosis at two health centres, and antenatal activities at one health centre. At the fourth health centre, TA providers focused equally across all components required to implement the Option $\mathrm{B}+$ guidelines. Neither the amount of TA time nor the focus explained differences in health centres' implementation of Option B+ guidelines.

Resources. When health centres were short on material resources, support providers delivered drugs, HIV testing kits, water purification packets, nutritional supplementation packets, printing services, mosquito bed nets, and point-ofcare and blood pressure machines covered by UNC Project. They also helped tranport patient samples to laboriories for testing..

Figure 2 provides an overview of study findings related to the the support strategies provided to improve the implementation of Option B+ guidelines and the contextual factors that influenced support strategies and guideline implementation.

\section{Implementation of the Option B+ guidelines}

On a scale of 0 (not implementing) to 3.0 (always implementing), overall implementation of Option $\mathrm{B}+$ ranged from 2.3 to 2.8 , with ratings higher at highperforming centres (2.5 and 2.8.) than at low-performing ones (2.3 and 2.3; Table 2). All centres performed well on components completed between the antenatal and labor and delivery periods and performed less well on those completed during the post-delivery period, such as early identification and diagnosis of HIV-exposed children at 6 weeks, 12 and 24 months. In addition, only one centre fully implemented community sensitisation and mobilisation activities and only one properly documented all rendered activities.

\section{Contextual factors that influenced support strategies and Option B+ implementation}

Factors influencing support strategies. Two contextual factorsstaffing shortages and transportation challenges-varied between high-performing health centres and low-performing ones. Low performing health centres had fewer staff than the high performing ones (Table 1); as a result, TA providers spent time collaborating in service delivery and did not have time to meet with staff to provide feedback. As one support recipient stated:
Monday to Sunday, 24/7, you are found at this facility because patients do come any time to seek. for help, so we do not have time to rest... if someone is alone like the way I am, that means, there is no other person to relieve me, so it is a challenge [to meet with the TA providers]. Let's say I go out... it means all the services will not be done (medical assistant, low- performing centre).

Transportation also affected the delivery of TA to high- and low-performing health centres. The high performing centres were close to well paved roads and the low performing centres were not (Table 1). TA providers drove motorcycles to three of the centres and a car to the fourth centre (high performing). TA providers made all planned visits to high performing centres but could not travel by motorcycle on unpaved roads to low performing centres during rainy season (December through April).

Factors influencing Option B+ implementation. Contextual factors influencing Option B+ guidelines implementation were number of the health centre staff, adequacy of clinic infrastructure (buildings, exam rooms, equipment), availability of HIV test kits, and magnitude of populations served. Both high-performing health centres reported adequate staffing. According to one support recipient:
...to be honest, as a health centre we have adequate staff. I can compare with other health centres which have just one nurse; but we have three nurses, two clinicians... We also have [name of the organisation withheld] staff that follow pregnant women up to time of delivery..... (nurse midwife technician, high- performing centre).

In contrast, both low-performing health centres reported a critical shortage of staff, too little service space/infrastructure to accommodate all units required to implement the Option $\mathrm{B}+$ guidelines, frequent shortages of HIV testing kits, and a patient population that included people from surrounding catchment areas with no maternity or ART services. An informant shared: The workload here is high; it is very high but staff that are supposed to do the job are very few....It is a very big challenge because the work that is done here requires more people than we are... as a result the HIV positive women are put on hold until all babies who come for immunizations are assisted. As the time goes by, that woman just leaves the facility without being assisted (medical assistant, low-performing centre).

\section{Discussion}

This qualitative descriptive exploratory multiple-case study https://dx.doi.org/10.4314/mmj.v33i3.5 
examined how the support and delivery systems interacted to implement Option B+ guidelines in Malawi and explored the contextual factors that influenced both implementation and support. Specifically, this study describes $\mathrm{MoH}$ and health centre staff experience with support strategies (i.e., tools, staff training, technical assistance, and resources) and how they built capacity to better implement Option B+ guidelines. The study also identified two contextual factors (staffing shortages and transportation challenges) that negatively influenced the delivery of those strategies. Inadequate clinic staff, space/infrastructure, HIV testing kits, and magnitude of the served population were contextual factors that impeded implementation of the Option $\mathrm{B}+$ core activities in the community, antenatal unit, maternity/labor ward and under-five/early infant diagnosis. In contrast to activities implemented post-delivery period, all centres performed well on the antenatal and labor and delivery of Option $\mathrm{B}+$ components. Prior studies of implementation support often fail to describe healthcare providers' experience with implementation strategies or contextual factors that influenced strategy delivery or impact, thereby limiting efforts to replicate, target, or further refine implementation strategies ${ }^{17}$. This study addresses that gap by describing the delivery and use of training, technical assistance, tools, and resources to support implementation and how those strategies impacted health centre capacity to implement Option B+ guidelines. The study also identified salient contextual factors that influenced guideline implementation, many of which align with those identified in other implementation studies in low-resource settings ${ }^{18}$ and in other studies of the implementation of Option $\mathrm{B}+$ guidelines, such as periodic shortages of HIV testing kits and ART drugs ${ }^{19,20}$. In contrast to this study's focus on support providers and health centre staff, prior research also has identified factors at the community level that affect HIV positive women including lack of transportation, work conflicts, and stigma associated with $\mathrm{HIV}^{20,21}$. A distinct feature of this study is the focus on contextual factors that influenced not only guideline implementation but also the delivery of support strategies and the finding that transportation challenges played a central role in limiting the delivery of technical assistance to some of the health centres.

Study findings suggest that the delivery of implementation support strategies will be most successful if they are adapted to the needs of the specific contexts where support will be provided.

Findings from this study suggest the need to expand the ISF framework to include "resources" as a new strategy, particulary when examining the provision of implementation support to low resource countries. ${ }^{10,11}$ This strategy may be needed to overcome barriers to implementation. For example, a meta-ethnography of 32 qualitative studies of Option B + in Sub-Saharan Africa identified lack of resources (e.g., staff, space in health facilities, and drugs) as a barrier to implementation ${ }^{20}$. The UNC project's provision of test kits, medications, and transportation was central to ensuring full implementation of Option B+ guidelines. Despite the value of providing resources as a support strategy, this strategy may be difficult to sustain overtime. In addition to providing resources, support systems also need to build delivery system to attain resources once the supporting system is no longer able to act as a safety net ${ }^{10}$.

Study findings on implementation of Option B+ guidelines are similar to previous studies confirming progress on HIV testing and lifelong ART for HIV-infected pregnant and breastfeeding women and persistent gaps in HIV testing for exposed infants ${ }^{1,8,21-23}$. One factor that may contribute to this gap is the finding that HIV+ women are more likely to be lost to follow up when they were started on ART in compliance with Option B+ guidelines (i.e, they are pregnant) as compared to those who are started on ART in response to physical symptoms ${ }^{22}$. Additional factors that may contribute to this gap include health workers' negative attitudes towards HIV positive women, lack of capacity to collect blood samples from exposed babies, poor follow up of babies born at home, and structural barriers such as poverty, lack of transportation, work conflicts, and fear of disclosure and HIV related stigma ${ }^{22,23}$. This gap demonstrates the critical need for further research to improve rates of HIV testing for exposed infants at 6 weeks, 6 months and 12 months post-delivery as the most challenging component of implementation of Option B+ guidelines. Some strategies that have shown promise for improved EID activities include pairing mothers with HIV positive peer mentors ${ }^{24}$ and increasing men's involvement in maternal and child health activities ${ }^{25,26}$.

\section{Study Limitations}

Only four of 134 Malawi health centres were included in the study, thus limiting application of findings. Inclusion of other support providers, health centre staff, and managers may have identified other factors affecting implementation and support.

\section{Implications for theory, practice, and research}

Findings support and augment the strategies described in the ISF for Dissemination and Implementation. ${ }^{10,11}$ Study findings also suggest that delivery of support strategies is most successful when adapted to needs of specific contexts where support will be provided. Support providers are advised to assess the context to design and integrate support strategies into existing systems and manage local barriers to implementation. Had UNC Project identified salient contextual factors upfront, tailored support strategies may have accommodated differing levels of staffing and accessibility across health centres and explored options for onsite training.

The long-term goal of implementation support is to build the delivery system's capacity to implement and sustain guidelines independent of the support system ${ }^{11}$, yet some support strategies were inconsistent with this goal (e.g., provision of resources and use of TA providers as collaborators in the delivery of services). To ensure sustainability, rather than transiently filling gaps in capacity, support strategies need to focus on building delivery system's long term capacity to implement guidelines.

Further research is needed to better understand the role of contextual factors and how best to empower and enable health centres to be self-sufficient. To eliminate HIV in SubSaharan Africa, evidence is needed to determine the most effective ways to provide support and determine where support providers should focus their TA time in order to have the greatest impact on implementation.

\section{Conclusions}

This qualitative study describes implementation support strategies provided by UNC Project and explored factors that may explain variations between low- and highperforming health centres. Data from four health centres https://dx.doi.org/10.4314/mmj.v33i3.5 
provided detailed descriptions of these health centres to guide design of support strategies for Option $\mathrm{B}+$ guidelines implementation or other evidence-based guidelines in low resource settings.

\section{Dedication}

This paper is dedicated to the late Professor Charles van der Horst who was part of the first author's dissertation committee and contributed to the whole process of the study up to writing of this paper. Dr. Van der host provided critical feedback to the study design and findings. May the soul of Professor van der Horst rest in peace.

\section{Declarations}

\section{Ethics approval and consent to participate}

This study was approved by two Institutional Review Boards: The University of North Carolina at Chapel Hill Research and Ethics Committee (approval \#14-1441) and the Malawi National Health Sciences Research and Ethics Committee (approval \# 1302).

\section{Consent for publication}

As stated on design section above, permission was sought from the Malawi Ministry of Health HIV/AIDS office, the district health offices, and all study health centres through their directors and managers. Written informed consent was obtained from all individual study informants prior to data collection.

\section{Availability of data and material}

The datasets used and/or analysed during the current study are available from the corresponding author on reasonable request.

\section{Competing interests}

The authors declare that they have no competing interests.

\section{Funding}

This study is a $\mathrm{PhD}$ dissertation of the first author. Academic requirements were funded by the UNC AIDS International Training and Research Program grant award/ NIH/Fogarty HIV Research Training Program award (AITRP)-DHHS NIH 5 D43 TW001039-14 and the Gilead Foundation through the Gilead Training Fellowship of the HIV Care in Malawi. The "Off-Campus Dissertation Research Fellowship" from UNC-Chapel Hill Graduate School supported the first author with living expenses during data collection. The National Institutes of Health Office of the Director, Fogarty International Centre, Office of AIDS Research, National Cancer Centre, National Heart, Blood, and Lung Institute, and the NIH Office of Research for Women's Health through the Fogarty Global Health Fellows Program Consortium comprised of the University of North Carolina, John Hopkins, Morehouse, and Tulane (R25TW009340) supported research activities such buying of stationery, printing of data collection tools and consent forms, hiring of transport to study clinics and transport reimbursement of the study participants.

\section{Authors' contributions}

C.C. Z. proposed the study, collected, analysed, and interpreted data and drafted this manuscript. J. L. was a chair of this dissertation study and worked tirelessly to guide the first author from proposal through data collection, analysis, and interpretation and is a major contributor of this manuscript. B. M. and G. S were members of the dissertation committee who read and provided feedback on every part of writing phase of this study and also read and approved this final manuscript.

\section{Acknowledgements}

Acknowledgement go to Dr. Cathie Fogel who was part of the first authors' dissertation committee, Dr. Paul Mihas of the Odom Institute of UNC Chapel Hill and Dr. Jinbing Bai who was a $\mathrm{PhD}$ candidate at UNC Chapel Hill, School of nursing and taught the first author analytical skills that were used to analyze data for this study; the academic and research sponsors as outlined above and the sponsors of the "Linda Waring Matthews Research Fund Scholarship and "James and Patricia Leak Fund for Nursing Research funding" for providing financial support; the Malawi Ministry of Health; the UNC Project in Malawi; the study clinics and informants for support and providing thorough information that allowed this study to respond to its questions. Thanks also go to the research assistants: Davie Malinkhwa, Cecilia Massa, Mercy Tsidya, and Stevens Makina, who helped with data transcription and running of the study in Malawi. Lastly, Dr Ashley Bryant of UNC-Chapel Hill, school of nursing supported editing of this manuscript, her support is highly appreciated.

\section{Authors' information}

C.C.Z. worked as a research nurse/midwife for twelve years in Malawi prior to coming to the University of North Carolina at Chapel Hill for her $\mathrm{PhD}$ during which this was conducted. She now works as a Behavioral scientist for UNC Project in Malawi; J. L. is an Associate Professor at UNC Chapel Hill school of nursing and chaired this dissertation research; G. S and B.M are both Professor Emeriti of UNC Chapel Hill school of nursing. Both B.M and G.S were part of this dissertation committee.

\section{References}

1.Joint United Nations Programme on HIV/AIDS (UNAIDS). Global AIDS Updates. 2016. Available from http://www.unaids.org/sites/ default/files/media_asset/global-AIDS-update-2016_en.pdf

2.National Statistical Office (NSO) Malawi and ICF. Malawi Demographic and Health Survey 2015-16. 2017. Available from:

https://dhsprogram.com/pubs/pdf/FR319/FR319.pdf.

3.Malawi Ministry of Health., Malawi Government: 2012 Global AIDS Response Progress Report: Malawi Country Report for 2010 and 2011. 2012. Available from http://www.unaids.org/en/dataanalysis/ knowyourresponse/countryprogressreports/2012countries/ce_MW_ Narrative_Report\%5B1\%5D.pdf

4. Malawi Ministry of Health, Malawi Integrated Guidelines for Clinical Management of HIV in Children and Adults, HIV and AIDS Unit. 2011, Malawi Ministry of Health: Lilongwe. Available from http:// www.hivunitmohmw.org/uploads/Main/Malawi\%20Integrated\%20 Guidelines $\% 20$ for $\% 20$ Clinical $\% 20$ Management $\% 20$ of $\% 20 \mathrm{HIV} \% 20$ 2011\%20First\%20Edition.pdf

5. Jamieson DJ, Chasela CS, Hudgens MG, King CC, Kourtis AP, Kayira D, et al. Maternal and infant antiretroviral regimens to prevent postnatal HIV-1 transmission: 48-week follow-up of the BAN randomised controlled trial. Lancet. 2012;379(9835):2449-58.6.

6. Joint United Nations Programme on HIV/AIDS (UNAIDS). Together we will end AIDS. 2012; Available from: http://www.unaids. org/en/media/unaids/contentassets/documents/epidemiology/2012/ gr2012/20121120_UNAIDS_Global_Report_2012_en.pdf.

7. Moses A, Zimba C, Kamanga E, Nkhoma J, Maida A, Martinson F, et al. Prevention of mother-to-child transmission: program changes and https://dx.doi.org/10.4314/mmj.v33i3.5 
the effect on uptake of the HIVNET 012 regimen in Malawi. AIDS. 2008;22(1):83-7.

8.Herce ME, Mtande T, Chimbwandira F, Mofolo I, Chingondole CK, Rosenberg NE, et al. Supporting Option B + scale up and strengthening the prevention of mother-to-child transmission cascade in central Malawi: results from a serial cross-sectional study. BMC Infect Dis. 2015;15:328.

9. van Lettow M, Landes M, van Oosterhout JJ, Schouten E, Phiri $\mathrm{H}$, Nkhoma E, et al. Prevention of mother-to-child transmission of HIV: a cross-sectional study in Malawi. Bull World Health Organ. 2018;96(4):256-65.

10.Wandersman A, Chien VH, Katz J. Toward an evidence-based system for innovation support for implementing innovations with quality: tools, training, technical assistance, and quality assurance/ quality improvement. Am J Community Psychol. 2012;50(3-4):445-59.

11.Wandersman A, Duffy J, Flaspohler P, Noonan R, Lubell K, Stillman $\mathrm{L}$, et al. Bridging the gap between prevention research and practice: the interactive systems framework for dissemination and implementation. Am J Community Psychol. 2008;41(3-4):171-81.

12.Yin RK. Case Study Research: design and methods. Los Angeles, CA: Sage Publications; 2013.

13.Miles MB, \& Huberman AM. Qualitative data analysis: an expanded sourcebook. Thousand Oaks, CA: Sage Publications;1994.

14.Baxter P, \& Jack, S. Qualitative Case Study Methodology: study design and implementation for novice researchers. The Qualitative report. 2008;13(4):544-59.

15.Creswell, JW. Qualitative inquiry \& research design: choosing among five approaches. Thousand Oaks: Sage Publications; 2007

16.Hsieh HF, Shannon SE. Three approaches to qualitative content analysis. Qual Health Res. 2005;15(9):1277-88

17.Proctor EK, Powell, B.J. \& McMillen, J.C. Implementation strategies: recommendations for specifying and reporting. Implement Sci. 2013;8(139)

18. Nguyen G, Costenbader E, Plourde KF, Kerner B, Igras S.
Scaling-up normative change interventions for adolescent and youth reproductive health: an examination of the evidence. J Adolesc Health. 2019;64(4s):S16-s30.

19. King R, Matovu JN, Rujumba J, Wavamunno P, Amone A, Gabagaya G, et al. PMTCT Option B+ 2012 to 2018 - Taking stock: barriers and strategies to improve adherence to Option $\mathrm{B}+$ in urban and rural Uganda. Afr J AIDS Res. 2020;19(2):135-46.

20. Williams SM, Renju J, Moshabela M, Wringe A. Understanding the influence of health systems on women's experiences of Option B+: a meta-ethnography of qualitative research from sub-Saharan Africa. Glob Public Health. 2021;16(2):167-85.

21. Ahoua L, Arikawa S, Tiendrebeogo T, Lahuerta M, Aly D, Becquet $\mathrm{R}$, et al. Measuring retention in care for HIV-positive pregnant women in Prevention of Mother-to-Child Transmission of HIV (PMTCT) option $\mathrm{B}+$ programs: the Mozambique experience. BMC Public Health. 2020;20(1):322.22.

22. Ahoua L, Tiendrebeogo T, Arikawa S, Lahuerta M, Aly D, Journot $\mathrm{V}$, et al. PMTCT care cascade and factors associated with attrition in the first four years after Option B+ implementation in Mozambique. Trop Med Int Health. 2020;25(2):222-35.

23. Diallo K, Kim AA, Lecher S, Ellenberger D, Beard RS, Dale H, et al. Early Diagnosis of HIV Infection in Infants - One Caribbean and Six Sub-Saharan African Countries, 2011-2015. MMWR Morb Mortal Wkly Rep. 2016;65(46):1285-90.

24. Wanga I, Helova A, Abuogi LL, Bukusi EA, Nalwa W, Akama E, et al. Acceptability of community-based mentor mothers to support HIVpositive pregnant women on antiretroviral treatment in western Kenya: a qualitative study. BMC Pregnancy Childbirth. 2019;19(1):288.

25. Besada D, Rohde S, Goga A, Raphaely N, Daviaud E, Ramokolo $\mathrm{V}$, et al. Strategies to improve male involvement in PMTCT Option $\mathrm{B}+$ in four African countries: a qualitative rapid appraisal. Glob Health Action. 2016;9:33507.

26. Chi BH, Mbori-Ngacha D, Essajee S, Mofenson LM, Tsiouris F, Mahy M, et al. Accelerating progress towards the elimination of mother-to-child transmission of HIV: a narrative review. J Int AIDS Soc. 2020;23(8):e25571. 